\title{
Role of Campylobacter jejuni gamma-glutamyl transpeptidase on epithelial cell apoptosis and lymphocyte proliferation
}

\author{
Pauline Floch ${ }^{1,2}$, Vincent Pey ${ }^{1,2}$, Michel Castroviejo ${ }^{3}$, Jean William Dupuy ${ }^{4}$, Marc Bonneu ${ }^{4}$, \\ Anaïs Hocès de la Guardia ${ }^{1,2}$, Vincent Pitard ${ }^{5}$, Francis Mégraud ${ }^{1,2}$ and Philippe Lehours ${ }^{1,2,6^{*}}$
}

\begin{abstract}
Background: A gamma-glutamyl transpeptidase (GGT) is produced by up to 31\% of strains of Campylobacter jejuni isolates. C. jejuni GGT is close to Helicobacter pylori GGT suggesting a conserved activity but unlike the latter, C. jejuni GGT has not been studied extensively. In line with the data available for $\mathrm{H}$. pylori, our objectives were to purify $\mathrm{C}$. jejuni GGT from the bacteria, and to evaluate its inhibitory and proapoptotic activities on epithelial cells and human lymphocytes.

Methods: C. jejuni GGT was purified from culture supernatants by chromatography. After verification of the purity by using mass spectrometry of the purified enzyme, its action on two epithelial cell lines and human lymphocytes was investigated. Cell culture as well as flow cytometry experiments were developed for these purposes.

Results: This study demonstrated that C. jejuni GGT is related to Helicobacter GGTs and inhibits the proliferation of epithelial cells with no proapoptotic activity. C. jejuni GGT also inhibits lymphocyte proliferation by causing a cell cycle arrest in the GO/G1 phase. These effects are abolished in the presence of a specific pharmacological inhibitor of GGT.

Conclusion: C. jejuni GGT activity is comparable to that of other Epsilonproteobacteria GGTs and more generally to Helicobacter bilis (inhibition of epithelial cell and lymphocyte proliferation, however with no proapoptotic activity). It could therefore be considered as a pathogenicity factor and promote, via the inhibition of lymphocyte proliferation, the persistence of the bacteria in the host. These observations are consistent with a role of this enzyme in the pathophysiology of chronic infections associated with C. jejuni.
\end{abstract}

Keywords: Campylobacter jejuni, GGT, Lymphocytes, Epithelial cells

\section{Background}

Campylobacter jejuni is the main Campylobacter species isolated from humans. The $C$. jejuni reservoir consists essentially of the digestive tract of birds, including poultry. Transmission to humans occurs mainly indirectly via food or contaminated water [1]. In humans, Campylobacters induce enteritis generally with a favourable evolution after a few days but with potential complications like systemic infections or post-infectious diseases (Guillain-Barré syndrome). C. jejuni may also be involved

\footnotetext{
*Correspondence: philippe.lehours@u-bordeaux2.fr

'Bacteriology Laboratory, University of Bordeaux, F-33000 Bordeaux, France ${ }^{2}$ INSERM U853, F-33000 Bordeaux, France

Full list of author information is available at the end of the article
}

in immunoproliferative small intestinal disease (IPSID) [2] which belongs to the group of digestive mucosa associated lymphoid tissue (MALT) lymphomas.

In Helicobacter pylori, a bacterium close to C. jejuni, the role of gamma-glutamyl transpeptidase (GGT) has been extensively studied [3-5]. GGT is an enzyme belonging to the family of $\mathrm{N}$-terminal nucleophile hydrolases, present in prokaryotes and eukaryotes, playing a major role in the degradation of glutathione. GGTs of distant species (mammals and bacteria) often exhibit a high protein sequence identity $(>25 \%)[6,7]$.

H. pylori GGT has been the subject of numerous studies. It is present in $100 \%$ of the strains and is constitutively expressed. It can reach the periplasmic space thanks 
to its signal peptide. It is synthesized as an inactive $60 \mathrm{kDa}$ precursor which undergoes autocatalytic cleavage resulting in an active heterodimer composed of two subunits of 20 and $40 \mathrm{kDa}$ respectively. The small subunit plays a key role in the autocatalytic and enzymatic activity of GGT; it includes the active site of the enzyme [6,8]. This enzyme is not essential to the bacteria, as ggt gene deletion does not inhibit bacterial growth, but it provides an advantage in gastric colonization [3]. H. pylori GGT also plays a role in the inhibition of T-lymphocyte proliferation by blocking the cell cycle in the G1 phase [5]. In addition, several studies have shown that $H$. pylori GGT has a proapoptotic effect on human gastric epithelial cells (AGS line) [9-11].

C. jejuni GGT has been studied less. It is present in up to $31 \%$ of strains [12] and has 67 to $69 \%$ of amino-acid identity with $H$. pylori GGT. The cleavage site, the essential residues for enzymatic activity, substrate recognition and catalytic activity for $H$. pylori GGT are conserved in C. jejuni GGT. It allows $C$. jejuni to metabolize glutamine and glutathione as a source of amino acids and possibly to persist in the intestine [13]. A Finnish study showed that C. jejuni GGT could be a marker of severity of infection, in particular for bloody diarrhea [14].

In this study, we used phylogenetic and functional approaches to analyze $C$. jejuni GGT. We showed that $C$. jejuni GGT is related phylogenetically to Helicobacter GGTs and, like H. pylori GGT, C. jejuni GGT inhibits lymphocyte and epithelial cell proliferation. The inhibition observed was mediated by an apoptosis-independent mechanism, suggesting a conserved function among GGTs in Epsilonproteobacteria.

\section{Results}

\section{Phylogenetic analysis}

The phylogenetic position of $C$. jejuni GGT among Epsilonproteobacteria was analyzed (Additional file 1: Figure S1). C. jejuni GGT was closer to H. bilis, Helicobacter canis and Helicobacter trogontum GGTs than to H. pylori GGTs. C. jejuni GGTs appeared to be highly conserved, including those of $H$. pylori.

\section{C. jejuni GGT purification}

C. jejuni GGT was purified from a bacterial supernatant. Briefly, as described in Materials and Methods, proteins from a supernatant were first precipitated with ammonium sulfate. The supernatant was then dialyzed and purified by two ion-exchange chromatographies. To determine the effectiveness of the purification, the dialysate, the product obtained after the first chromatography and the final product were analyzed by migration on a SDS-PAGE gel and Coomassie blue staining (Figure 1A). Efficient purification was observed between the dialysate, the product of the first chromatography and the final product.
Two bands at approximately 40 and $20 \mathrm{kDa}$ were observed on the gel after the final purification, which is consistent with the expected molecular weights of the large and small subunit of C. jejuni GGT, respectively. These bands were cut and analyzed by mass spectrometry (after extraction and protein digestion). The results showed the presence of $C$. jejuni GGT with a significant number of peptides (Figure 1B): the amino-acids found in the $40 \mathrm{kDa}$ band represent $73.6 \%$ of the protein sequence of the large subunit of C. jejuni GGT and those found in the $20 \mathrm{kDa}$ band represent $68.8 \%$ of the protein sequence of the small subunit.

\section{C. jejuni GGT effects on epithelial cells}

The gastric epithelial cell line AGS was cultured for $24 \mathrm{~h}$ in media supplemented with 2.5 to $320 \mathrm{ng} / \mathrm{mL}$ of purified GGT with or without acivicin to determine the optimal concentration to evaluate GGT activity. At high concentrations epithelial cell proliferation was strongly inhibited with or without GGT inactivation with acivicin suggesting an artifactual phenomenon. This artifactual effect was lost at lower concentrations (Figure 2A). At $10 \mathrm{ng} / \mathrm{mL}$ of GGT, a significant reduction of AGS cell proliferation was still observed whereas acivicin restored a normal proliferation rate. This concentration was finally chosen as the lowest GGT concentration to be used. The activity of GGT at $10 \mathrm{ng} / \mathrm{mL}$ was also verified on Caco- 2 cell proliferation (Figure 2B). Compared to AGS cells, GGT also had a significant effect on intestinal cell proliferation.

Trypan blue staining and cell counts after a $24 \mathrm{~h}$ incubation with $C$. jejuni GGT was used to verify that this inhibitory effect was not due to a cell death phenomenon, rather to a cell proliferation arrest (data not shown).

The activity of C. jejuni GGT on apoptosis was then studied by flow cytometry on AGS cells only. Compared to the control, $C$. jejuni GGT induced a significant increase in the percentage of apoptosis (Figure 3A). However, C. jejuni GGT preincubation with acivicin did not decrease the percentage of epithelial cells undergoing apoptosis. In conclusion, the proapoptotic activity observed in the presence of $C$. jejuni GGT did not seem to be dependent on the presence of GGT (Figure 3B) but on contaminant proteins even when they were in very small amounts in the final product.

\section{C. jejuni GGT effects on human lymphocytes}

Lymphocyte proliferation was measured after 4 days of culture in the presence of. C. jejuni GGT. A significant inhibition of lymphocyte proliferation was observed. Preincubation of $C$. jejuni GGT with acivicin or heat inactivation of the enzyme, restored a level of lymphocyte proliferation similar to that of the lymphocytes alone (Figure 4). The inhibition of lymphocyte proliferation could therefore be attributed to the GGT. 
No significant apoptosis was observed in the presence of C. jejuni GGT. The lymphocyte cell cycle was however disturbed and, in particular, a cell cycle arrest in the G0/G1 phase was found (Table 1) (Additional file 2: Figure S2). No disturbance was observed when $C$. jejuni GGT was inactivated with acivicin or heating.

In conclusion, C. jejuni GGT exhibited significant biological effects on human lymphocytes.

\section{Discussion}

Because of the conserved protein homology of $C$. jejuni GGT with $H$. pylori GGT, the objectives of the present study were to determine whether $C$. jejuni GGT had the same properties as $H$. pylori GGT to inhibit 1) epithelial cell proliferation via a pro-apoptotic mechanism and 2) human lymphocyte proliferation. These data could be strong arguments to better understand the pathogenicity of $C$. jejuni and to consider C. jejuni GGT as an important pathogenicity factor of this bacterium as well.

C. jejuni GGT was highly conserved among the $C$. jejuni strains. As already shown by Skarp-de Haan CP et al., [15] C. jejuni GGT was also very close to Helicobacter GGTs, in particular those from $H$. bilis, $H$. canis and $H$. trogontum, which suggests a conserved activity between these GGTs. C. jejuni GGT was purified directly from culture supernatants. This technical approach allowed the isolation of the protein directly from the bacterium, avoiding any potential problems of protein solubility or refolding as described in a previous publication [7].

In line with results concerning $H$. pylori, $H$. bilis, and $H$. suis GGTs $[7,10,16,17]$, an inhibition of epithelial cell proliferation was observed for C. jejuni GGT. This biological activity seemed to be independent of the cell origin (gastric or intestinal). It has been suggested that $H$. pylori and $H$. suis GGTs exert their inhibitory activity indirectly via the formation of metabolites during transpeptidation $[5,16]$. This point should be investigated further for $C$. jejuni GGT. Contrary to what has been described for $H$. pylori and $H$. suis GGTs $[9-11,16]$, this inhibitory effect does not depend on a proapoptotic activity of $C$. jejuni GGT. H. pylori and H. suis GGTs are indeed responsible for the apoptosis of human gastric epithelial cells (AGS cell line), via the activation of caspases 3 and 9, Bax, a decreased expression of antiapoptotic proteins $\mathrm{Bcl}-2$ and $\mathrm{Bcl}-\mathrm{xl}$, and the release of

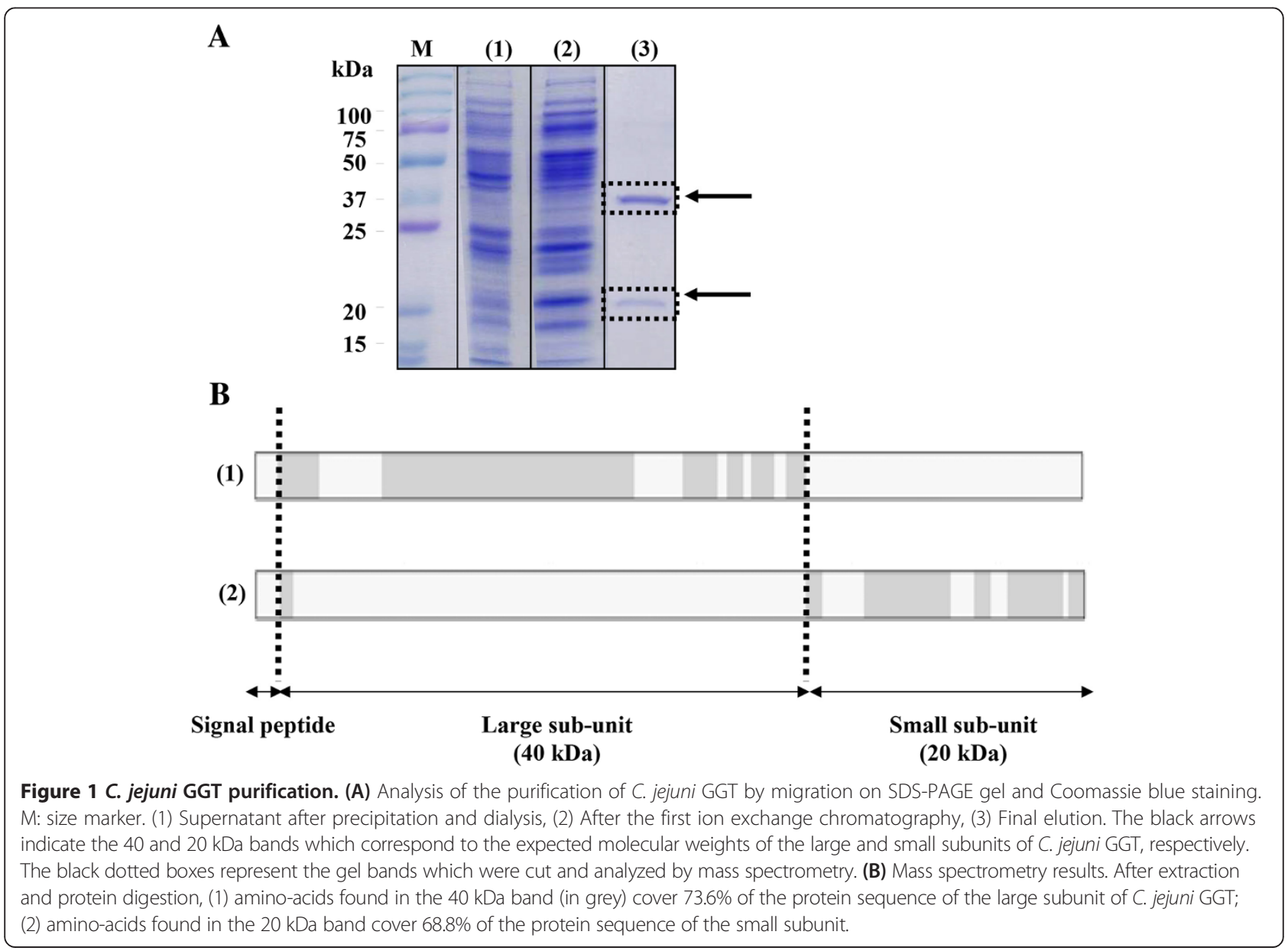




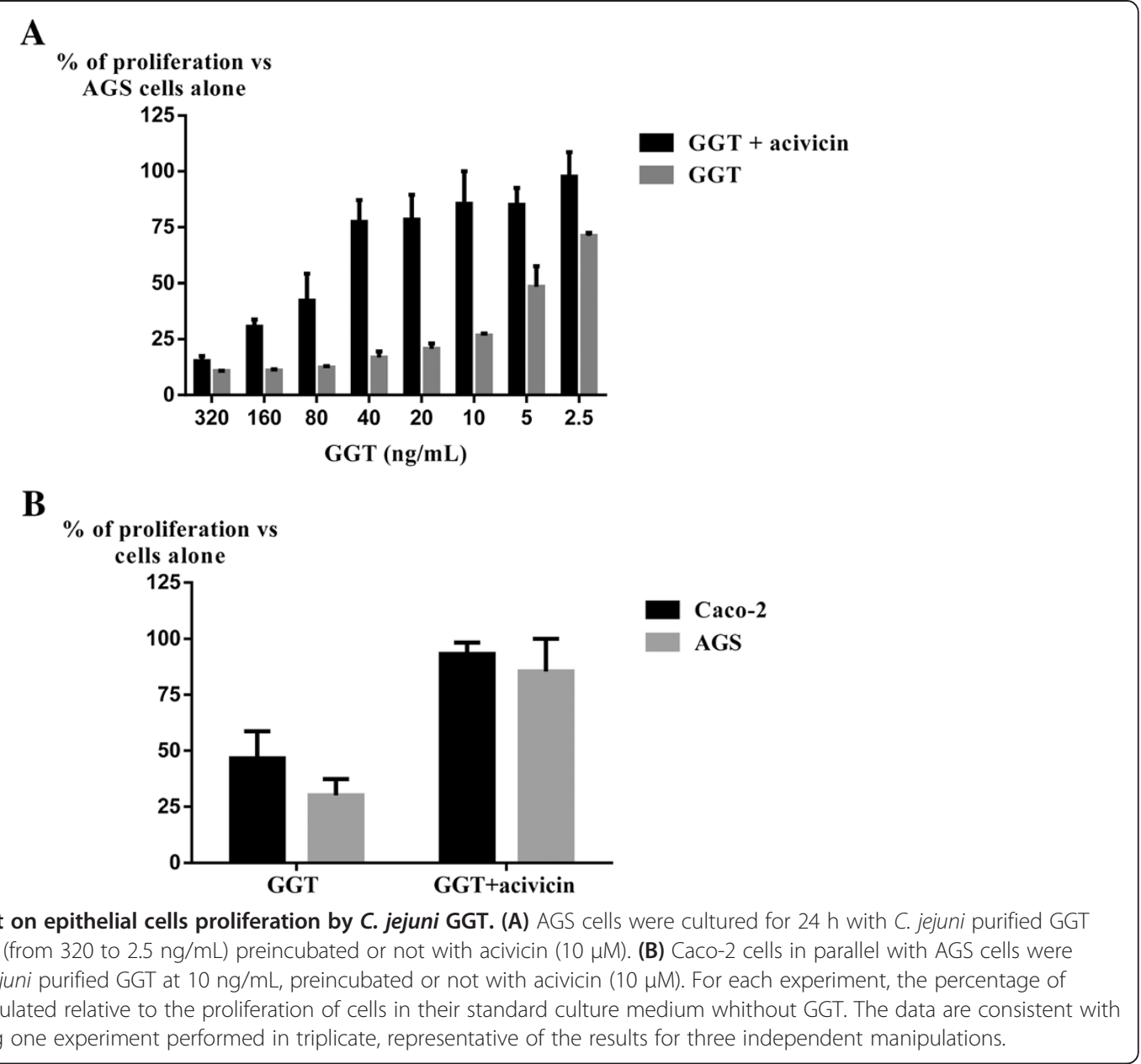

cytochrome $\mathrm{c}[10,11]$ or via the increase in $\mathrm{H}_{2} \mathrm{O}_{2}$ concentration due to glutathione catabolism by GGT $[16,18]$. A necrotic phenomenon was also described for $H$. suis GGT. In the study of Shibayama et al. fetal calf serum (FCS) deprivation in the culture medium was carried out before the apoptosis study [9]. Therefore if the proapoptotic activity is detectable only under stress conditions, it may simply be a technical artifact. Finally, our results are similar to those of Rossi et al. with $H$. bilis [7], which interestingly is one of most closely related phylogenetically to C. jejuni GGT [15].

The role of C. jejuni GGT in the inhibition of lymphocyte proliferation with cell cycle arrest in the G0/G1 phase was also demonstrated in our study. This property is shared by $H$. pylori, $H$. bilis and $H$. suis GGTs $[4,5,7,19,20]$. As for $H$. pylori GGT, the inhibition of lymphocyte proliferation is not dependent on an apoptotic phenomenon. Schmees et al. showed that H. pylori GGT acts on the cell cycle via a decrease in cellular levels of Ras-dependent track mediators [5]. The cell cycle arrest in the G1 phase by $H$. pylori GGT is characterized by an increase in p27 and CDK inhibitor levels and a decrease in cyclins. As for its activity on epithelial cells, GGT appears to have an indirect action via the metabolites formed during transpeptidation [20]. These mechanisms have to be validated for C. jejuni GGT.

\section{Conclusions}

C. jejuni GGT promotes the persistence of intestinal colonization in animals [21] and in our study it inhibited the proliferation of human epithelial cells and lymphocytes. These inhibitory activities are shared by $H$. pylori GGT $[4,5,19]$. C. jejuni GGT could therefore be considered as a pathogenicity factor for this bacterium, fostering the persistence of the infection in humans via the inhibition of lymphocyte proliferation.

\section{Methods}

Bacterial strains, cell lines, culture conditions

Eleven C. jejuni strains named 2003-198, 2002-200, 2004-304, 2003-383, 2004-438, 2002-608, 2002-646, 2007-741, 2003-795, 2003-1129, and 2003-1206 were obtained from the National Reference Center on Campylobacters and Helicobacters $(\mathrm{CNRCH})$ strain collection 
A

(2)

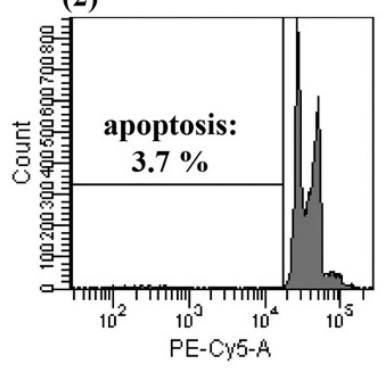

(1)

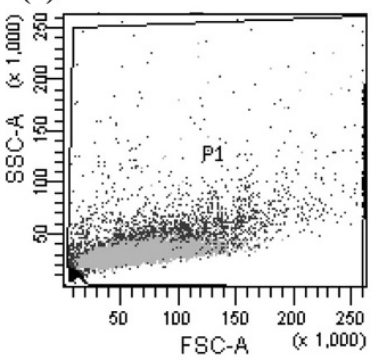

(3)

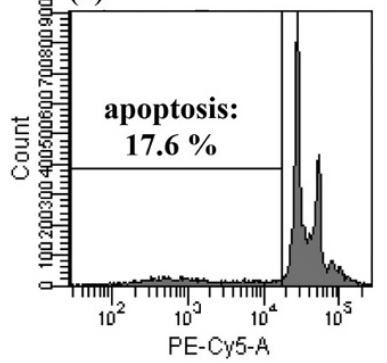

(4)

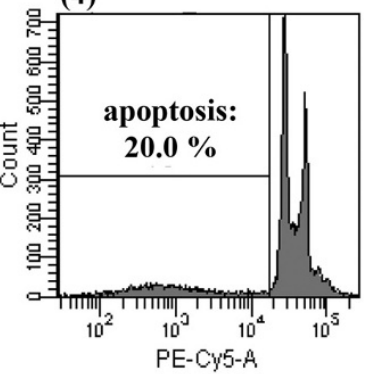

B

\% of apoptotic cells

60

50

40

30

20

10

0
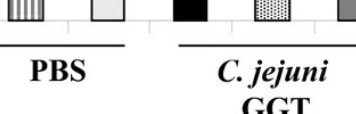

向 AGS cells alone

$\square$ AGS cells + acivicin

GGT

䍤 GGT + acivicin

heat inactivated GGT

Staurosporine

Figure 3 Activity of C. jejuni GGT on AGS cells apoptosis. (A) 1 - Selection of the population of interest (P1) depending on the size (FSC-A) and cell density (SSC-A). The population was chosen as large as possible in order to properly select the apoptotic cells that may have varied cytological features. Fluorescence emitted at cyanine 5 wavelength (PE-Cy-5) was analyzed based on the number of events in the selected population: diploid cells are separated from hypodiploid cells (apoptotic cells). The proportion of epithelial cells in apoptosis was determined by the ratio between hypodiploid cells and the number of events in the P1 population. Typical cytometry results are shown for 2- control AGS cells, 3- AGS cells with C. jejuni GGT (10 ng/mL) and 4- AGS cells with C. jejuni GGT (10 ng/mL) preincubated with acivicin (10 $\mu$ M). (B) AGS cells were cultured for $24 \mathrm{~h}$ with C. jejuni GGT $(10 \mathrm{ng} / \mathrm{mL})$ and preincubated or not with acivicin $(10 \mu \mathrm{M})$. A significant difference was observed between control cells and the cells with C. jejuni GGT. However, preincubation for $2 \mathrm{~h}$ at $37^{\circ} \mathrm{C}$ with acivicin or heat inactivation $\left(70^{\circ} \mathrm{C}, 20 \mathrm{~min}\right)$ of $\mathrm{C}$. jejuni GGT had no effect. Staurosporine $(10 \mu \mathrm{M})$ was used as the positive control. These data presented in $\mathbf{A}$ and $\mathbf{B}$, are consistent with the results obtained during the same manipulation carried out in triplicate, representative of the results for three independent manipulations. ${ }^{* * i n d i c a t e s ~ a ~}$ significant difference, $p<0.05$ versus cells in PBS alone; ns for a non-significant difference, $p>0.05$ ).

(Univ. Bordeaux, Bordeaux, France). They were received between 2002 and 2007. All of these strains were isolated from humans, essentially from faecal samples, and they were all identified at the species level by MALDI-TOF mass spectrometry [22]. They belong to Lior biotype III (hippurate,$+ \mathrm{H}_{2} \mathrm{~S}+$ and DNase -), in which the prevalence of GGT is more important (60\% according to personal data) than in the other biotypes (15-20\%). They were used to assess the diversity of GGT genetics in $C$. jejuni. C. jejuni strain 81116 (a kind gift from Dr D. Newell) was used to purify GGT and to study C. jejuni GGT activity on epithelial cells and lymphocytes. It was selected for its GGT activity, as previously described by Barnes et al. [21].

All strains were grown on horse blood agar (bioMérieux, Marcy l'Etoile, France) in a microaerobic atmosphere at 


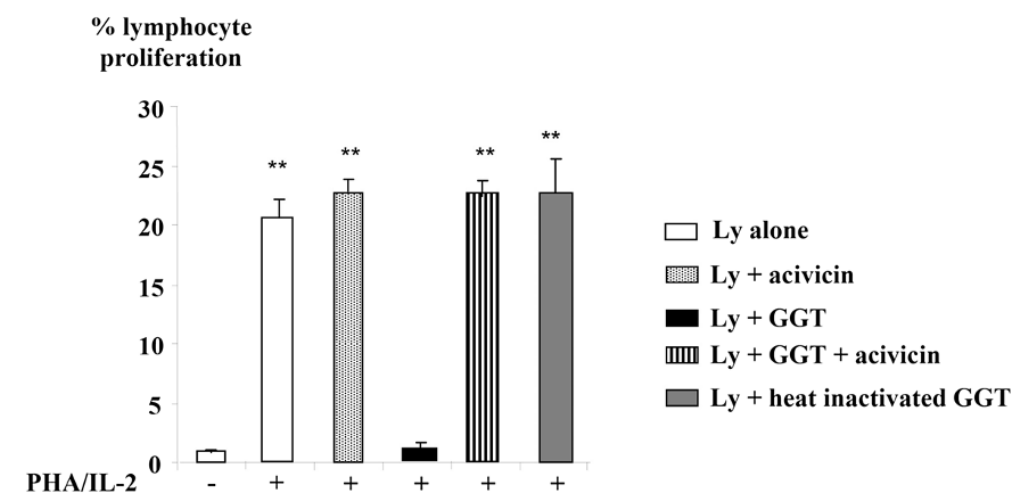

Figure 4 Inhibitory effect on lymphocyte proliferation of $C$. jejuni GGT. Lymphocytes were cultured with C. jejuni purified GGT (10 ng/mL). The ability of lymphocyte proliferation was verified by the action of phytohemagglutinin (PHA, $1 \mathrm{mg} / \mathrm{mL}$ ) associated with interleukin-2 (IL-2, $20 \mathrm{U} / \mathrm{mL}$ ). Proliferation was measured after 4 days of culture by BrdU incorporation. Preincubation with acivicin $(10 \mu \mathrm{M})$ or the prior inactivation by heat (20 min, $70^{\circ} \mathrm{C}$ ) of $\mathrm{C}$. jejuni GGT restored lymphocyte proliferation. These data are consistent with the results obtained during a manipulation performed in triplicate and representative of the results for three independent manipulations. (**indicates a significant difference, $p<0.05, c 0 m p a r e d$ to lymphocytes alone (Ly)).

$37^{\circ} \mathrm{C}$. A microscopic control was systematically performed to check the morphology and mobility and standard bacteriological tests (Gram staining, catalase, oxidase) were carried out as well.

The human intestinal epithelial cell lines AGS (stomach cell line) and Caco-2 (colon cell line) were used. The AGS cells in RPMI medium (Invitrogen) supplemented with $10 \%$ FCS (Invitrogen) and $50 \mu \mathrm{g} / \mathrm{mL}$ of vancomycin (Sandoz, Levallois Perret, France) and the Caco-2 cells were grown in Modified Eagle's Medium (MEM) (Invitrogen, Fisher Scientific SAS, Illkirch Cedex, France) supplemented with 1\% Minimum Essential Amino Acids (MEAA) (Invitrogen).

Lymphocytes were purified from peripheral blood from hemochromatosis patients by Ficoll gradient with therapeutic phlebotomy performed regularly at the EFS (French Blood Establishment, Aquitaine-Limousin) (No. EFS CPS 10.41 Convention). Blood was collected in bags (MSE 6500 L) (Macopharma, Tourcoing, France) in the presence of an anticoagulant (sodium citrate).

\section{Phylogenetic analysis}

The ggt genes of C. jejuni strains 2003-198, 2002-200, 2004-304, 2003-383, 2004-438, 2002-608, 2002-646, 2007-741, 2003-795, 2003-1129, and 2003-1206 were amplified and sequenced using external and internal gene-specific primers (Table 2). The sequences obtained were translated into protein sequences using the EMBOSS software Transeq (http://www.ebi.ac.uk/Tools/st/ emboss_transeq/). GGT sequences of 5 C. jejuni strains for which the genome is completely sequenced, were selected: C. jejuni strains 81116 [23], 81176 [24], M1 [25], ICDCCJ07001 [26] and C. jejuni subsp. doylei strain 269.97 (RefSeq NC_009707.1). GGTs of 8 published $H$. pylori strains were also selected: strains 26695 [27], 099 [28], HPAG1 [29], 908 [30], P12 [31], Shi470 [32], B38 [33] and B45 [34], as well as GGTs of $H$. canis, H. bilis, $H$. trogontum, H. felis [35], $H$. salomonis, $H$. suis [36], $H$. bizzozeronii [37], H. cetorum, $H$. acinonychis [38] and $H$. mustelae [39] strains. GGT sequences of 2 Arcobacter species (related to Campylobacter species) were added

Table 1 Distribution of cell cycle phases in lymphocytes cultured with $C$. jejuni GGT

\begin{tabular}{llll}
\hline & \multicolumn{3}{c}{ Cell cycle phase } \\
\cline { 2 - 4 } & G0/1 & \multicolumn{1}{c}{ S } & $0.2+/$ - 0.1 \\
\hline Ly & $99.0+/-0.2$ & $0.6+/-0.2$ & $11.1+/-1.3$ \\
Ly + PHA/IL-2 & $69.9+/-0.8$ & $18.0+/-0.7$ & $8.0+/-2.1$ \\
Ly + PHA/IL-2 + acivicin & $71.3+/-2.0$ & $18.0+/-0.7$ & $1.0+/-0.1$ \\
Ly + PHA/IL-2+ C. jejuni GGT & $97.5+/-0.6$ & $1.2+/-0.5$ & $12.3+/-0.7$ \\
Ly + PHA/IL-2+ C. jejuni GGT + acivicin & $68.6+/-1.9$ & $17.7+/-0.9$ & $9.6+/-0.8$ \\
Ly + PHA/IL-2+ heat inactivated C. jejuni GGT & $71.5+/-1.0$ & $16.8+/-2.0$ & \\
\hline
\end{tabular}

Flow cytometry study by Nicoletti assay after 4 days of culture with C. jejuni GGT (10 ng/mL). Percentage of cells in G0/G1, $\mathrm{S}$ and G2/M phase depending on growth conditions. These data are consistent with the results obtained during a manipulation performed in triplicate representative of the results for two independent manipulations. (Ly: lymphocytes, PHA: phyto hemagglutinin, IL-2: interleukin 2). 
Table 2 Oligonucleotides used in this study

\begin{tabular}{ll}
\hline Oligonucleotides (size) & \multicolumn{1}{c}{ Sequence (5'-3') } \\
\hline F-GGT (23 bp) & GGGTAAATAAGAGTAGATTC \\
R-GGT (21 bp) & CTTATAAAGGCGGAATGCC \\
F1GGT (20 bp) & TGCTTTGCTGTAGTGCATC \\
R1GGT (20 bp) & TGCTTACAGCATTGCCTTG \\
F2GGT (20 bp) & TAGGCTITTGCGGTGGTAG \\
R2GGT (20 bp) & CAGGAGATCCTGTGCCTGTG \\
F3GGT (21 bp) & TTATCGCAAAGGAAGTCCTG \\
R3GGT (20 bp) & AGCATCAGGACCTCCTTG \\
\hline
\end{tabular}

bp: base pairs.

to our selection. Phylogenetic analysis of GGT amino-acid sequences was conducted in MEGA4 software using the Minimum Evolution (ME) method after alignment in the ClustalW2 software (http://www.ebi.ac.uk/Tools/msa/clustalw2/) and 1,000 repetitions of this analysis [40].

Nucleotide and protein sequences for the 11 C. jejuni GGTs sequenced in the present study are available in Genebank (EMBL) under the following accession numbers: KF985027, KF991209, KF991210, KF991211, KF991212, KF991213, KF991214, KF991215, KF991216, KF991217, KF991218 for the strains 2002-200, 2002-608, 2002-646, 2003-198, 2003-383, 2003-1129, 2003-1206, 2004-304, 2004-438, 2007-741, and 2003-795 respectively.

\section{Enzyme assay for GGT activity}

GGT enzymatic activity was determined by the spectrophotometric method described by Meister et al. [41]. The assay solution contained $20 \mathrm{mM}$ of glycylglycine (Sigma Aldrich, Saint-Quentin Fallavier, France), $300 \mathrm{mM}$ of L- $\gamma$-glutamyl-p-nitroanilide (Sigma Aldrich) and $60 \mathrm{mM}$ of TRIS $\mathrm{pH}$ 8. The reaction mixture $(5 \mu \mathrm{l}$ of GGT in $200 \mu \mathrm{L}$ of assay solution) was incubated at $37^{\circ} \mathrm{C}$ and analyzed by spectrophotometry at $405 \mathrm{~nm}$ to evaluate the release of p-nitroanilide (yellow compound). The activity of acivicin (Santa Cruz Biotechnology, Heidelberg, Germany), a pharmacological inhibitor of GGT, was also tested $(10 \mu \mathrm{M})$ after a $2 \mathrm{~h}$ preincubation at $37^{\circ} \mathrm{C}$ as well as GGT heat inactivation at $70^{\circ} \mathrm{C}$ for $20 \mathrm{~min}$

\section{C. jejuni GGT purification}

A bacterial supernatant of C. jejuni 81116 was prepared by incubating the strain in $1 \mathrm{~L}$ of PBS overnight at $37^{\circ} \mathrm{C}$ with orbital shaking $(150 \mathrm{rpm})$. After centrifugation at $10,000 \mathrm{rpm}$ for $10 \mathrm{~min}$, the supernatant was recovered. Solid ammonium sulfate (Sigma Aldrich) was added to the cell extract to $90 \%$ saturation, and the mixture was stirred at $4^{\circ} \mathrm{C}$ for $2 \mathrm{~h}$. The precipitate was removed by centrifugation at $12,000 \mathrm{rpm}$ for $30 \mathrm{~min}$ at $4^{\circ} \mathrm{C}$ and dissolved in $6 \mathrm{~mL}$ of dialysis buffer (TRIS $50 \mathrm{mM}, \mathrm{NaCl}$
$25 \mathrm{mM}, \mathrm{pH} 8$ ). This solution was dialyzed twice against $1 \mathrm{~L}$ of the same buffer for $2 \mathrm{~h}$ and overnight at $4^{\circ} \mathrm{C}$. The GGT activity was tested on $5 \mu \mathrm{L}$ of the dialyzed solution according to the method of Meister et al. described above [41].

One $\mathrm{mL}$ of the dialyzed solution was applied to a MonoQ ${ }^{\circ}$ HiTrap column (GE Healthcare, Aulnay sous Bois, France) equilibrated with $50 \mathrm{mM}$ TRIS pH 8 (Buffer A). Elution was performed at a flow rate of $1 \mathrm{~mL} /$ min with a gradient of $\mathrm{NaCl}$ stepwise $(0.08 ; 0.25 ; 0.35$ and $1 \mathrm{M}$ ) in buffer A. $330 \mu \mathrm{l}$ fractions were collected and tested for GGT activity as previously described. The active fractions were combined and SDS-PAGE was performed with $12 \%$ polyacrylamide running gel and 5\% polyacrylamide stacking gel. After electrophoresis, the gel was stained with Coomassie blue.

The active fraction was then purified by a second ion exchange chromatography (MonoQ ${ }^{\circ}$ HiTrap column, $1 \mathrm{~mL}, \mathrm{GE}$ Healthcare). Elution was performed at a flow rate of $1 \mathrm{~mL} / \mathrm{min}$ with a linear gradient of $\mathrm{NaCl}(0.08$ to $0.5 \mathrm{M})$. The active fraction was not retained by the column and was eluted directly. SDS-PAGE and Coomassie blue staining were performed. The active fraction was precipitated with ammonium sulfate (90\% saturation) at $4^{\circ} \mathrm{C}$ for $2 \mathrm{~h}$. The precipitate was removed by centrifugation at $12,000 \mathrm{rpm}$ for $30 \mathrm{~min}$ at $4^{\circ} \mathrm{C}$ and dissolved in $400 \mu \mathrm{L}$ of dialysis buffer. This solution was dialyzed twice for $2 \mathrm{~h}$ each time against $500 \mathrm{~mL}$ of the same buffer at $4^{\circ} \mathrm{C}$. SDS-PAGE and Coomassie blue staining were performed. The bands of interest were cut and analyzed by mass spectrometry at the Functional Genomics Platform of the University of Bordeaux. The protein concentration was determined spectrometrically using the Bradford method with bovine serum albumin (BSA) as a standard (Biorad, Marnes La Coquette, France). The GGT activity was again evaluated as described above.

\section{Mass spectrometry}

Sample preparation: Each SDS-PAGE band was cut into $1 \mathrm{~mm} \times 1 \mathrm{~mm}$ gel pieces. Gel pieces were destained in $25 \mathrm{mM}$ ammonium bicarbonate, 50\% acetonitrile (ACN) and shrunk in ACN for $10 \mathrm{~min}$. After ACN removal, gel pieces were dried at room temperature. Proteins were first reduced in $10 \mathrm{mM}$ dithiothreitol, $100 \mathrm{mM}$ ammonium bicarbonate for $30 \mathrm{~min}$ at $56^{\circ} \mathrm{C}$ then alkylated in $100 \mathrm{mM}$ iodoacetamide, $100 \mathrm{mM}$ ammonium bicarbonate for $30 \mathrm{~min}$ at room temperature and shrunk in ACN for $10 \mathrm{~min}$. After $\mathrm{ACN}$ removal, gel pieces were rehydrated with $100 \mathrm{mM}$ ammonium bicarbonate for $10 \mathrm{~min}$ at room temperature. Before protein digestion, gel pieces were shrunk in $\mathrm{ACN}$ for $10 \mathrm{~min}$ and dried at room temperature. Proteins were digested by incubating each gel slice with $10 \mathrm{ng} / \mu \mathrm{l}$ of trypsin (T6567, Sigma-Aldrich) 
in $40 \mathrm{mM}$ NH4HCO3, $10 \% \mathrm{ACN}$, rehydrated at $4^{\circ} \mathrm{C}$ for $10 \mathrm{~min}$, and finally incubated overnight at $37^{\circ} \mathrm{C}$. The resulting peptides were extracted from the gel in three steps: an initial incubation in $40 \mathrm{mM}$ ammonium bicarbonate, $10 \% \mathrm{ACN}$ for $15 \mathrm{~min}$ at room temperature and two incubations in $47.5 \% \mathrm{ACN}, 5 \%$ formic acid for $15 \mathrm{~min}$ at room temperature. The three collected extractions were pooled with the initial digestion supernatant, dried in a SpeedVac, and resuspended in $25 \mu \mathrm{L}$ of $0.1 \%$ formic acid before nanoLC-MS/MS analysis.

NanoLC-MS/MS analysis: Online nanoLC-MS/MS analyses were performed using an Ultimate 3000 system (Dionex, Amsterdam, The Netherlands) coupled to a nanospray LTQ Orbitrap XL mass spectrometer (Thermo Fisher Scientific, Bremen, Germany). Ten $\mu \mathrm{L}$ of each peptide extract were loaded on a $300 \mu \mathrm{m}$ ID $\times$ mm PepMap $\mathrm{C}_{18}$ precolumn (LC Packings, Dionex, Sunnyvale, CA, USA) at a flow rate of $30 \mu \mathrm{L} / \mathrm{min}$. After $5 \mathrm{~min}$ of desalting, peptides were separated on a $75 \mu \mathrm{m} \mathrm{ID} \times 15 \mathrm{~cm} \mathrm{C}{ }_{18}$ Pep$\mathrm{Map}^{\text {tw }}$ column (LC packings) with a 5-40\% linear gradient of solvent B for $108 \mathrm{~min}$ (solvent A was 0.1 formic acid in $5 \% \mathrm{ACN}$ and solvent B was $0.1 \%$ formic acid in $80 \%$ ACN). The separation flow rate was set at $200 \mathrm{~nL} / \mathrm{min}$. The mass spectrometer operated in a positive ion mode at a $1.8-\mathrm{kV}$ needle voltage and a $27-\mathrm{V}$ capillary voltage. Data were acquired in a data-dependent mode alternating an FTMS scan survey over the range $\mathrm{m} / \mathrm{z} 300-1700$ with the resolution set to a value of 60,000 at $\mathrm{m} / \mathrm{z} 400$ and 6 ion trap MS/MS scans with Collision Induced Dissociation (CID) as the activation mode. MS/MS spectra were acquired using a $3-\mathrm{m} / \mathrm{z}$ unit ion isolation window and normalized collision energy of 35 . Mono-charged ions and unassigned charge-state ions were rejected from fragmentation. Dynamic exclusion duration was set to $30 \mathrm{sec}$.

Database search and results processing: Mascot and Sequest algorithms through Proteome Discoverer 1.4 Software (Thermo Fisher Scientific) were used for protein identification in batch mode by searching against a C. jejuni UniProt database (44,546 entries). Two missed enzyme cleavages were allowed. Mass tolerances in MS and MS/MS were set to $10 \mathrm{ppm}$ and $0.8 \mathrm{Da}$. Oxidation of methionine and carbamidomethylation on cysteine were searched as variable modifications. Peptide validation was performed using Percolator algorithm [42] and only "high confidence" peptides were retained corresponding to a $1 \%$ false positive rate at peptide level.

\section{C. jejuni GGT activity on epithelial cells}

Cell proliferation: Epithelial cells were cultured in 96well plates for $48 \mathrm{~h}$. The effect of purified GGT on these lines was evaluated at different concentrations (2.5 to $320 \mathrm{ng} / \mathrm{mL}$ ) after $24 \mathrm{~h}$ of treatment with the MTT
Formazan kit (Sigma-Aldrich). GGTs, either preincubated for $2 \mathrm{~h}$ in the presence of acivicin or previously heat-inactivated $\left(70^{\circ} \mathrm{C}, 20 \mathrm{~min}\right)$, were also tested.

Cell apoptosis: AGS cells were cultured in 24-well plates for $48 \mathrm{~h}$. The pro-apoptotic effect of GGT $(10 \mathrm{ng} / \mathrm{mL})$ with and without acivicin after $24 \mathrm{~h}$ of treatment was evaluated using the Nicoletti method [43]. Staurosporine $(10 \mu \mathrm{M})$ (Sigma-Aldrich), a proapoptotic compound, was used as a positive control. Briefly, adherent cells were trypsinized, washed and centrifuged for $5 \mathrm{~min}$ at 3,000 rpm. The cell pellet was resuspended in $100 \mu \mathrm{L}$ of Nicoletti buffer $(0.1 \%$ sodium citrate, $0.1 \%$ Triton X-100, $50 \mathrm{mg} / \mathrm{L}$ of propidium iodide in distilled water). The FACS CantoII cytometer (BD Biosciences, Le Pont de Claix, France) was used for data acquisition.

\section{C. jejuni GGT activity on lymphocytes}

Lymphocytes were cultured in 24-well plates $\left(1.10^{6}\right.$ cells/well) for 4 days at $37^{\circ} \mathrm{C}$ in a $5 \% \mathrm{CO}_{2}$ atmosphere in RPMI supplemented with $10 \%$ FCS and $50 \mu \mathrm{g} / \mathrm{mL}$ of vancomycin in the presence of purified GGT (10 $\mathrm{ng} / \mathrm{mL})$ with or without acivicin $(10 \mu \mathrm{M})$, and heatinactivated $\left(70^{\circ} \mathrm{C}, 20 \mathrm{~min}\right)$ or not. The proliferative capacity of lymphocytes was monitored using phytohemagglutinin (PHA, $1 \mu \mathrm{g} / \mathrm{mL}$ ) (Sigma Aldrich) and interleukin 2 (IL 2, $1000 \mathrm{U} / \mathrm{mL}$ ) (Chiron, Surennes, France) [19]. Lymphocyte proliferation was measured by BrdU incorporation ( 5 bromo 2 ' deoxyuridine) (BD Biosciences) with flow cytometry (FACS CantoII) using a method previously validated in the laboratory [19]. This incorporation was revealed using an anti-BrdU antibody coupled to the fluorochrome fluorescein isothiocyanate (FITC) (BD Biosciences). Stimulation of this fluorochrome by the laser cytometer allowed an analysis of the cells based on their size and density and a record of the proportion of those that have been specifically recognized by the anti-BrdU antibody. The results were analyzed using CellQuest (BD Biosciences) software and were used to determine the percentage of proliferated cells.

During the same experiment, the percentage of cells undergoing apoptosis and the cell cycle were both evaluated by the Nicolleti method. Lymphocytes were centrifuged for $10 \mathrm{~min}$ at $1,500 \mathrm{rpm}$ and resuspended in $100 \mu \mathrm{l}$ of Nicoletti buffer.

\section{Statistical analysis}

Statistical analyses were performed using the MannWhitney test (SPSS Version 16 software). This is a nonparametric test which is used to test the equality of distribution of two independent sets of values to be compared ( $\mathrm{p}<0.05)$. 


\section{Additional files}

Additional file 1: Figure S1. Tree based on amino-acid sequences of different bacterial GGTs. The evolutionary history was inferred using the method of "Minimum Evolution" and the evolutionary distances were calculated using the matrix method of Dayhoff. The scale indicates the amino-acid substitutions. The numbers next to the branches indicate the robustness of the separation of the branches in the tree obtained ( $>70 \%$, analysis repeated 1,000 times)

Additional file 2: Figure S2. Example of cell cycle evaluation by flow cytometry (Nicoletti assay). (1) Selection of the population of interest (P2) by freeing aggregated cells that give false cells in the G2/M phase and taking into consideration the width of the emission wavelength of phycoerythrin (PE-W) according to the peak area (PE-A). From P2, Graphs (2) control lymphocytes, (3) Lymphocytes with C. jejuni GGT (10 ng/mL) and (4) lymphocytes with $C$. jejuni GGT (10 $\mathrm{ng} / \mathrm{mL}$ ) preincubated with acivicin (10 $\mu \mathrm{M}$ ) allow a distinction between G0/1 (P3), S (P4) and G2/M (P5) lymphocytes.

\section{Abbreviations}

GGT: Gamma-glutamyl transpeptidase; PI: Propidium iodure Ly: Lymphocytes.

\section{Competing interests}

The authors declare that they have no competing interests.

\section{Authors' contributions}

PF, VPey, AHDLG and JWD performed the experiments. PF, PL, FM, JWD wrote the manuscript. PL, PF and MC designed the experiments. VPitard, MB supervised some of the data analysis. All authors read and approved the final manuscript.

\section{Authors' information}

FM and PL are the head and co-head of the National Reference Center for Campylobacters and Helicobacters, respectively.

\section{Acknowledgements}

The authors thank Armelle Menard for advice in GGT purification and the Veterinary Laboratories Agency - Weybridge (New Haw, Addlestone, Surrey KT15 3NB, UK) and especially Dr Diane Newell for the kind gift of the C. jejuni strain 81116, and Lindsay Mégraud for English revision of the manuscript. A. Hocès de la Guardia received funding from the French Ministry of Research.

\section{Author details}

${ }^{1}$ Bacteriology Laboratory, University of Bordeaux, F-33000 Bordeaux, France. ${ }^{2}$ INSERM U853, F-33000 Bordeaux, France. ${ }^{3}$ MCMP, UMR 5234, CNRS, University of Bordeaux, F-33000 Bordeaux, France. ${ }^{4}$ Centre de Génomique Fonctionnelle, Plateforme Protéome, University of Bordeaux, F-33000 Bordeaux, France. ${ }^{5}$ CNRS, UMR 5164, CIRID, University of Bordeaux, F-33000 Bordeaux, France. ${ }^{6}$ INSERM U853, Bacteriology Laboratory, Université de Bordeaux (site Carreire), F-33076 Bordeaux, France.

Received: 5 February 2014 Accepted: 8 April 2014

Published: 12 June 2014

\section{References}

1. Mégraud F, Bessede E, Lehours P: Infections à Campylobacters. In EMC (Elsevier Masson SAS Paris) 2010, Maladies Infectieuses. 2010:1-10. paper 8-027-A-10.

2. Lecuit M, Abachin E, Martin A, Poyart C, Pochart P, Suarez F, Bengoufa D, Feuillard J, Lavergne A, Gordon JI, Berche P, Guillevin L, Lortholary O: Immunoproliferative small intestinal disease associated with Campylobacter jejuni. N Engl J Med 2004, 350:239-248.

3. Chevalier C, Thiberge JM, Ferrero RL, Labigne A: Essential role of Helicobacter pylori gamma-glutamyltranspeptidase for the colonization of the gastric mucosa of mice. Mol Microbiol 1999, 31:1359-1372.

4. Gerhard M, Schmees C, Voland P, Endres N, Sander M, Reindl W, Rad R, Oelsner M, Decker T, Mempel M, Hengst L, Prinz C: A secreted low-molecular-weight protein from Helicobacter pylori induces cell-cycle arrest of T cells. Gastroenterology 2005, 128:1327-1339.
5. Schmees C, Prinz C, Treptau T, Rad R, Hengst L, Voland P, Bauer S, Brenner L, Schmid RM, Gerhard M: Inhibition of T-cell proliferation by Helicobacter pylori gamma-glutamyl transpeptidase. Gastroenterology 2007, 132:1820-1833.

6. Boanca G, Sand A, Okada T, Suzuki H, Kumagai H, Fukuyama K, Barycki Jj: Autoprocessing of Helicobacter pylori gamma-glutamyltranspeptidase leads to the formation of a threonine-threonine catalytic dyad. J Biol Chem 2007, 282:534-541.

7. Rossi M, Bolz C, Revez J, Javed S, El-Najjar N, Anderl F, Hyytiainen $\mathrm{H}_{4}$ Vuorela P, Gerhard M, Hanninen ML: Evidence for conserved function of gamma-glutamyltranspeptidase in Helicobacter genus. PLoS One 2012, 7:e30543.

8. Boanca G, Sand A, Barycki JJ: Uncoupling the enzymatic and autoprocessing activities of Helicobacter pylori gammaglutamyltranspeptidase. J Biol Chem 2006, 281:19029-19037.

9. Shibayama K, Kamachi K, Nagata N, Yagi T, Nada T, Doi Y, Shibata N, Yokoyama K, Yamane K, Kato H, linuma Y, Arakawa Y: A novel apoptosisinducing protein from Helicobacter pylori. Mol Microbiol 2003, 47:443-451.

10. Kim KM, Lee SG, Park MG, Song JY, Kang HL, Lee WK, Cho MJ, Rhee KH, Youn HS, Baik SC: Gamma-glutamyltranspeptidase of Helicobacter pylori induces mitochondria-mediated apoptosis in AGS cells. Biochem Biophys Res Commun 2007, 355:562-567.

11. Kim KM, Lee SG, Kim JM, Kim DS, Song JY, Kang HL, Lee WK, Cho MJ, Rhee KH, Youn HS, Baik SC: Helicobacter pylori gamma-glutamyltranspeptidase induces cell cycle arrest at the G1-S phase transition. J Microbiol 2010, 48:372-377.

12. de Haan CP, Llarena AK, Revez J, Hanninen ML: Association of Campylobacter jejuni metabolic traits with multilocus sequence types. Appl Environ Microbiol 2012, 78:5550-5554.

13. Hofreuter D, Novik V, Galan JE: Metabolic diversity in Campylobacter jejuni enhances specific tissue colonization. Cell Host Microbe 2008, 4:425-433.

14. Feodoroff B, Ellstrom P, Hyytiainen H, Sarna S, Hanninen ML, Rautelin H: Campylobacter jejuni isolates in Finnish patients differ according to the origin of infection. Gut Pathog 2010, 2:22.

15. Skarp-de Haan CP, Culebro A, Schott T, Revez J, Schweda EK, Hanninen ML, Rossi M: Comparative genomics of unintrogressed Campylobacter coli clades 2 and 3. BMC Genomics 2014, 15:129.

16. Flahou B, Haesebrouck F, Chiers K, Van Deun K, De Smet L, Devreese B, Vandenberghe I, Favoreel H, Smet A, Pasmans F, D'Herde K, Ducatelle R: Gastric epithelial cell death caused by Helicobacter suis and Helicobacter pylori gamma-glutamyl transpeptidase is mainly glutathione degradation-dependent. Cell Microbiol 2011, 13:1933-1955.

17. Javed S, Mejias-Luque R, Kalali B, Bolz C, Gerhard M: Helicobacter bilis gamma-glutamyltranspeptidase enhances inflammatory stress response via oxidative stress in colon epithelial cells. PLoS One 2013, 8:e73160.

18. Gong M, Ling SS, Lui SY, Yeoh KG, Ho B: Helicobacter pylori gammaglutamyl transpeptidase is a pathogenic factor in the development of peptic ulcer disease. Gastroenterology 2010, 139:564-573.

19. Ferrand J, Roumanes D, Pitard V, Moreau JF, Megraud F, Lehours P: Modulation of lymphocyte proliferation induced by gastric MALT lymphomaassociated Helicobacter pylori strains. Helicobacter 2008, 13:167-173.

20. Zhang G, Ducatelle R, Pasmans F, D'Herde K, Huang L, Smet A, Haesebrouck F, Flahou B: Effects of Helicobacter suis gamma-glutamyl transpeptidase on lymphocytes: modulation by glutamine and glutathione supplementation and outer membrane vesicles as a putative delivery route of the enzyme. PLoS One 2013, 8:e77966.

21. Barnes $I H$, Bagnall MC, Browning DD, Thompson SA, Manning G, Newell DG: Gamma-glutamyl transpeptidase has a role in the persistent colonization of the avian gut by Campylobacter jejuni. Microb Pathog 2007, 43:198-207.

22. Bessede E, Solecki O, Sifre E, Labadi L, Megraud F: Identification of Campylobacter species and related organisms by matrix assisted laser desorption ionization-time of flight (MALDI-TOF) mass spectrometry. Clin Microbiol Infect 2011, 17:1735-1739.

23. Pearson BM, Gaskin DJ, Segers RP, Wells JM, Nuijten PJ, van Vliet AH: The complete genome sequence of Campylobacter jejuni strain 81116 (NCTC11828). J Bacteriol 2007, 189:8402-8403.

24. Hofreuter D, Tsai J, Watson RO, Novik V, Altman B, Benitez M, Clark C, Perbost C, Jarvie T, Du L, Galan JE: Unique features of a highly pathogenic Campylobacter jejuni strain. Infect Immun 2006, 74:4694-4707.

25. Friis C, Wassenaar TM, Javed MA, Snipen L, Lagesen K, Hallin PF, Newell DG, Toszeghy M, Ridley A, Manning G, Ussery DW: Genomic characterization of Campylobacter jejuni strain M1. PLoS One 2010, 5:e12253. 
26. Zhang M, He L, Li Q, Sun H, Gu Y, You Y, Meng F, Zhang J: Genomic characterization of the Guillain-Barre syndrome-associated Campylobacter jejuni ICDCCJ07001 Isolate. PLoS One 2010, 5:e15060.

27. Tomb JF, White O, Kerlavage AR, Clayton RA, Sutton GG, Fleischmann RD, Ketchum KA, Klenk HP, Gill S, Dougherty BA, Nelson K, Quackenbush J, Zhou L, Kirkness EF, Peterson S, Loftus B, Richardson D, Dodson R, Khalak HG, Glodek A, McKenney K, Fitzegerald LM, Lee N, Adams MD, Hickey EK, Berg DE, Gocayne JD, Utterback TR, Peterson JD, Kelley JM, et al: The complete genome sequence of the gastric pathogen Helicobacter pylori. Nature 1997, 388:539-547.

28. Alm RA, Ling LS, Moir DT, King BL, Brown ED, Doig PC, Smith DR, Noonan B, Guild BC, deJonge BL, Carmel G, Tummino PJ, Caruso A, Uria-Nickelsen M, Mills DM, Ives C, Gibson R, Merberg D, Mills SD, Jiang Q, Taylor DE, Vovis GF, Trust TJ: Genomic-sequence comparison of two unrelated isolates of the human gastric pathogen Helicobacter pylori. Nature 1999, 397:176-180.

29. Oh JD, Kling-Backhed H, Giannakis M, Xu J, Fulton RS, Fulton LA, Cordum HS, Wang C, Elliott G, Edwards J, Mardis ER, Engstrand LG, Gordon J: The complete genome sequence of a chronic atrophic gastritis Helicobacter pylori strain: evolution during disease progression. Proc Natl Acad Sci U S A 2006, 103:9999-10004.

30. Devi SH, Taylor TD, Avasthi TS, Kondo S, Suzuki Y, Megraud F, Ahmed N: Genome of Helicobacter pylori strain 908. J Bacteriol 2010, 192:6488-6489.

31. Fischer W, Windhager $L$, Rohrer S, Zeiller M, Karnholz A, Hoffmann R, Zimmer R, Haas R: Strain-specific genes of Helicobacter pylori: genome evolution driven by a novel type IV secretion system and genomic island transfer. Nucleic Acids Res 2010, 38:6089-6101.

32. Kersulyte D, Kalia A, Gilman RH, Mendez M, Herrera P, Cabrera L, Velapatino B, Balqui J, Paredes Puente de la Vega F, Rodriguez Ulloa CA, Cok J, Hooper CC, Dailide G, Tamma S, Berg DE: Helicobacter pylori from Peruvian amerindians: traces of human migrations in strains from remote Amazon, and genome sequence of an Amerind strain. PLOS One 2010, 5:e15076.

33. Thiberge JM, Boursaux-Eude C, Lehours P, Dillies MA, Creno S, Coppee JY, Rouy Z, Lajus A, Ma L, Burucoa C, Ruskoné-Foumestraux A, Courillon-Mallet A, De Reuse H, Boneca IG, Lamarque D, Mégraud F, Delchier JC, Médigue C, Bouchier C, Labigne A, Raymond J: From array-based hybridization of Helicobacter pylori isolates to the complete genome sequence of an isolate associated with MALT lymphoma. BMC Genomics 2010, 11:368.

34. Lehours P, Vale FF, Bjursell MK, Melefors $\mathrm{O}$, Advani R, Glavas S, Guegueniat J, Gontier E, Lacomme S, Alves Matos A, Menard A, Mégraud F, Engstrand L, Andersson AF: Genome sequencing reveals a phage in Helicobacter pylori. MBio 2011, 2(6). doi:10.1128/mBio.00239-11. Print 2011.

35. Arnold IC, Zigova Z, Holden M, Lawley TD, Rad R, Dougan G, Falkow S, Bentley SD, Müller A: Comparative Whole Genome Sequence Analysis of the Carcinogenic Bacterial Model Pathogen Helicobacter felis. Genome Biol Evol 2011, 3:302-308.

36. Vermoote M, Vandekerckhove TT, Flahou B, Pasmans F, Smet A, De Groote D, Van Criekinge W, Ducatelle R, Haesebrouck F: Genome sequence of Helicobacter suis supports its role in gastric pathology. Vet Res 2011, 42:51.

37. Schott T, Rossi M, Hanninen ML: Genome sequence of Helicobacter bizzozeronii strain $\mathrm{CIII-1}$, an isolate from human gastric mucosa. J Bacteriol 2011, 193:4565-4566.

38. Eppinger M, Baar C, Linz B, Raddatz G, Lanz C, Keller H, Morelli G, Gressmann H, Achtman M, Schuster SC: Who ate whom? Adaptive Helicobacter genomic changes that accompanied a host jump from early humans to large felines. PLOS Genet 2006, 2:e120.

39. O'Toole PW, Snelling WJ, Canchaya C, Forde BM, Hardie KR, Josenhans C, Graham R, McMullan G, Parkhill J, Belda E, Bentley SD: Comparative genomics and proteomics of Helicobacter mustelae, an ulcerogenic and carcinogenic gastric pathogen. BMC Genomics 2010, 11:164.
40. Tamura K, Dudley J, Nei M, Kumar S: MEGA4: Molecular Evolutionary Genetics Analysis (MEGA) software version 4.0. Mol Biol Evol 2007, 24:1596-1599.

41. Meister A, Tate SS, Griffith OW: Gamma-glutamyl transpeptidase. Methods Enzymol 1981, 77:237-253.

42. Kall L, Canterbury JD, Weston J, Noble WS, MacCoss MJ: Semi-supervised learning for peptide identification from shotgun proteomics datasets. Nat Methods 2007, 4:923-925.

43. Nicoletti I, Migliorati G, Pagliacci MC, Grignani F, Riccardi C: A rapid and simple method for measuring thymocyte apoptosis by propidium iodide staining and flow cytometry. J Immunol Methods 1991, 139:271-279.

doi:10.1186/1757-4749-6-20

Cite this article as: Floch et al:: Role of Campylobacter jejuni gammaglutamyl transpeptidase on epithelial cell apoptosis and lymphocyte proliferation. Gut Pathogens 2014 6:20.

\section{Submit your next manuscript to BioMed Central and take full advantage of:}

- Convenient online submission

- Thorough peer review

- No space constraints or color figure charges

- Immediate publication on acceptance

- Inclusion in PubMed, CAS, Scopus and Google Scholar

- Research which is freely available for redistribution

Submit your manuscript at www.biomedcentral.com/submit
C Biomed Central 